Archived version from NCDOCKS Institutional Repository http://libres.uncg.edu/ir/asu/

Blackwell, C., \& McKee, M. (2012). Alchian and Allen visit the IRS: costly audits and taxpayer compliance.

Applied Economics Letters, 19(17), 1731-1734. doi:10.1080/13504851.2012.667541

\title{
Alchian and Allen visit the IRS: costly audits and taxpayer compliance
}

\author{
Calvin Blackwell and Michael McKee
}

\begin{abstract}
This article reports on the results from a small-scale investigation of the compliance effects of a costly pre-audit on tax compliance. The tax compliance game is modelled in three parts: a declaration phase, a pre-selection phase with a cost for taxpayers and an audit selection phase where all evaded income is discovered. While the theoretical predictions are ambiguous, the data from a series of laboratory experiments demonstrate that the presence of pre-audit costs leads to lower tax compliance.
\end{abstract}

Keywords: tax compliance; tax evasion; experiment; audit cost; audit 


\section{Introduction}

The individual compliance costs of the US personal income tax system are well documented. Slemrod and Bakija (1996) estimated compliance costs of the entire federal tax system to be $\$ 75$ billion, which yields an average cost of $\$ 650$ per person. Many argue that these costs contribute to the general dissatisfaction with the Internal Revenue Service (IRS). An interesting research question is the effect of these costs on taxpayer behaviour. What is less well investigated is the effect on taxpayer behavior when there is a cost associated with being audited that is independent of whether the taxpayer has evaded.

Alchian and Allen (1966) argued for the 'shipping the good apples out' phenomenon. In the presence of a cost (transportation) that is independent of quality, the shipper will find that the high-quality item will better absorb the 'fixed' (quality-independent) shipping charges. A costly audit may serve the same function - a taxpayer facing a certain cost of being audited may reason that some evasion is justified. In the absence of the penalty for noncompliance, an audit will cost the taxpayer the same whether income is fully disclosed or not.

Data from a series of laboratory experiments are used to investigate this question. Audited taxpayers must pay taxes and penalties on undeclared income, but in addition, taxpayers must prepare for (and endure) an audit. This process may involve finding records of deductions, expenses and income. This cost is nontrivial and will be incurred even if the subsequent audit reveals that the taxpayer was in compliance. That is, a substantial portion of the cost of the audit is a fixed cost. Even if the taxpayer feels confident that his/her tax return was correct, the tax code is sufficiently complex that there will be significant uncertainty as to whether the return was completed correctly.

\section{Theory}

The tax reporting process we use in this article has three stages. In stage 1 , the taxpayer selects how much income to declare. In stage 2, the tax agency decides which taxpayers are likely candidates. We model this process as stochastic, although it is easy to imagine this may not be the case, owing to auditors' past experiences, tips about evaders and so on. If a taxpayer is selected in stage 2 (we call this selected for a preaudit), that individual may be selected for an audit. In any case, the individual is required to present his/her information to the tax agency and incurs a fixed cost for providing this material. In stage 3 , the tax agency chooses where to deploy fully its auditing resources among the individuals selected for a pre-audit. The selection for a full-blown audit may be made based on the expected level of under-reporting, or it may be made randomly.

Taking the model introduced in Allingham and Sandmo (1972) as the base, we define the following variables: 
$y$ is the actual income received by taxpayer.

$x$ is the declared income for taxpayer.

$t$ is the tax rate on declared income.

$\theta$ is the penalty rate on undeclared income $(y-x)$.

$p_{S}$ is the probability of being selected for pre-audit.

$p_{A}$ is the probability of being selected for audit.

$c$ is the cost of pre-audit.

A taxpayer faces three possible outcomes:

WN, which is the wealth if not audited for taxpayer:

$$
W_{N}=y-t x
$$

WS, which is the wealth if pre-audited but not audited:

$$
W_{S}=y-t x-c
$$

WA, which is the wealth if audited:

$$
W_{A}=y-t x-c-\theta(y-x)
$$

We assume the taxpayer's attempts to maximize his/her expected utility of wealth, where utility is the familiar von Neumann-Morgenstern utility function $U=U(W)$, with $U 0$ $.0, \mathrm{U} 00,0$. We further assume..$t$ (the penalty for evading taxes is greater than the initial tax obligation) and that pS. pA. The individual wishes to maximize the expected utility with respect to declared income, $\mathrm{x}$ :

$$
E U=\left(1-p_{S}-p_{A}\right) U\left(W_{N}\right)+p_{S} U\left(W_{S}\right)+p_{A} U\left(W_{A}\right)
$$

The first-order condition for this maximization is

$$
\begin{aligned}
& \left(1-p_{S}-p_{A}\right) U^{\prime}\left(W_{N}\right)(-t)+p_{S} U^{\prime}\left(W_{S}\right)(-t) \\
& \quad+p_{A} U^{\prime}\left(W_{A}\right)(\theta-t)=0
\end{aligned}
$$

To find the effect of a change in the cost of selection, we differentiate the first-order condition with respect to c:

$$
\frac{\partial(\cdot)}{\partial c}=p_{S} U^{\prime \prime}\left(W_{S}\right)(t)+p_{A} U^{\prime \prime}\left(W_{A}\right)(t-\theta)
$$

Note that this derivative may be either positive or negative, depending on the level of absolute risk aversion.

\section{Experimental Design}


To test the behavioural response to costly audits, we conduct a series of laboratory experiments. The experiment setting is a modification of the design used by Alm et al. (1992). In each round the subject receives an income, in tokens, 2 which is determined by a random draw from a uniform distribution between 2 and 4 , in increments of 0.2 tokens and is known only by the subject. Once the subjects know their income, they are asked to declare anywhere from 0 to their entire income. After all subjects have declared their income, the experimenters randomly selected up to five subjects for a pre-check. All subjects selected for a pre-check incurred a cost of either 0.1 tokens (treatment 1) or 0.2 tokens (treatment 2). In the baseline setting the cost is set at 0 . Of the five subjects selected for a pre-check, one subject may have been selected for an audit (a 'check' according to the instructions).

The selection process for pre-checks and checks worked as follows. All subjects are assigned a number. Each subject has a bingo ball with their subject number placed in a cage, along with a number of blank bingo balls. The number of blank balls was determined in order to make the total number of balls in the cage 25 . Five balls were picked from the bingo cage without replacement. These corresponding subjects are those selected for a 'pre-check'. Of those five balls, the first ball was set to have been selected for both the pre-check and the check. All five balls are drawn prior to the numbers being announced. Technically our process does not exactly conform to the model; instead of sequential selections, the subjects face only one. Our design avoids the problem of compound lotteries. By collapsing the two stages we eliminate the compound lottery. Given the structure of the balls in the bingo cage, the probability of being selected for a pre-check for each subject was 0.2 , while the probability of being selected for an audit was 0.04 . We selected these parameters to allow us to compare our results with previous research in this area, as well as to accord with typical random selection employed by the IRS.

The experiment continues for 25 rounds (although this is not announced to the subjects). Each round the subjects receive income, declare income, pay taxes and face the audit process described above. The subjects learn the audit results and have their balances updated each round. When the session is completed, the subjects are paid their accumulated earnings in private.

In all sessions, the person running the experiment read the instructions aloud to the subjects while they followed along on their own copies. The instructions were written to be as context neutral as possible; terms such as 'audit' and 'tax' were replaced with neutral terms such as 'check' and 'rate', respectively. Next, the subjects were given the opportunity to ask questions. After the experimenters answered all questions, the subjects played three practice rounds. Again, the subjects could ask questions. After all questions were answered, the main experiment began. Earnings averaged approximately $\$ 15.00$ for a session lasting less than 45 minutes on average.

\section{Experimental Results}


Based on the fixed cost argument as proposed by Alchian and Allen, we predict that compliance will be lower when audits are themselves costly. Individuals facing the fixed cost of an audit will find the relative costs of evasion have fallen and will thus comply less.

Summary statistics by treatment are shown in Table 1, while the round-by-round compliance rates are shown in Fig. 1. Contrary to our expectations, we find that with high audit costs (cost $=0.2)$ compliance rates are very high initially. However, the compliance rates decline over time and end up below 20\%. With low audit costs (cost = $0.1)$ the compliance rates also decline over time. When there is zero cost associated with the audit event (fines are imposed only for evasion), the compliance rate is very steady throughout the session. This latter result is consistent with the prior results of Alm et al. (1992).

Table 1. Average compliance rates by treatment

\begin{tabular}{llll}
$\begin{array}{l}\text { Audit } \\
\text { cost }\end{array}$ & $\begin{array}{l}\text { Number of } \\
\text { participants }\end{array}$ & $\begin{array}{l}\text { Number of } \\
\text { rounds }\end{array}$ & $\begin{array}{l}\text { Average compliance } \\
\text { rate }(\%)\end{array}$ \\
\hline 0 & 12 & 25 & 26.5 \\
10 & 14 & 25 & 10.5 \\
20 & 12 & 25 & 32.2
\end{tabular}

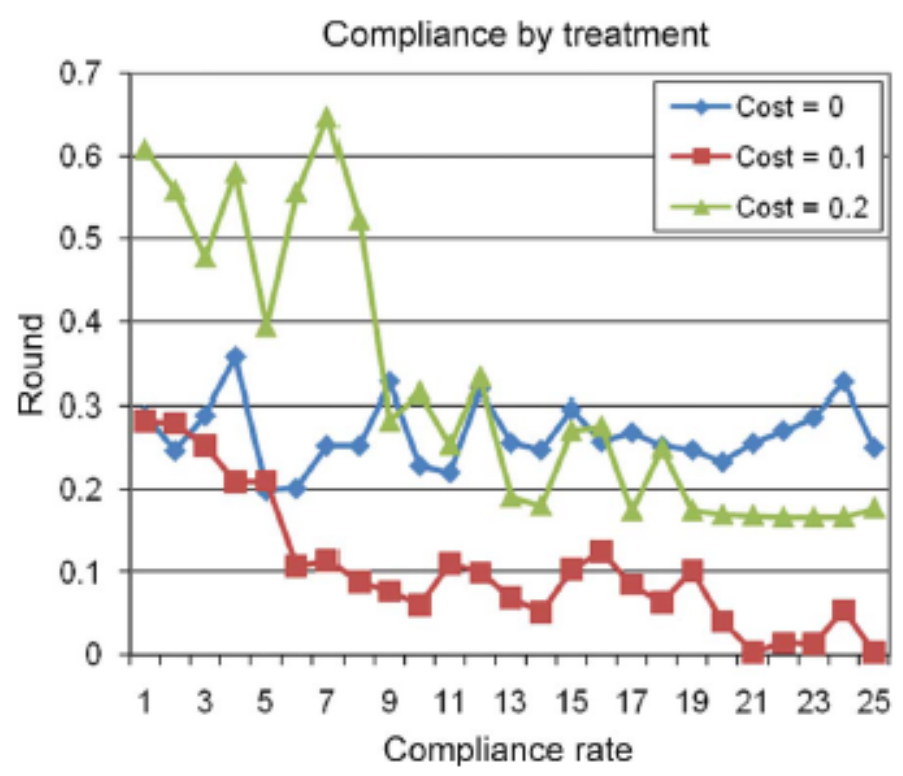

Fig. 1. Average compliance rates by round and treatment

To check the impression given by the summary statistics and the graphical analysis, we estimated by Generalized Least Squares (GLS) a simple random effects regression:

$$
\begin{aligned}
\operatorname{Comp}_{i, t}= & \beta_{0}+\beta_{1} \text { Inc }_{i, t}+\beta_{2} \text { Beg Bal }_{i, t}+\beta_{3} \text { Hi_Cost }_{i, t} \\
& +\beta_{4} \text { Lo_ }_{-} \text {Cost }_{i, t}+u_{i}+\varepsilon_{i, t}
\end{aligned}
$$


where Compi,t is the compliance rate for participant I in round $t$; Inci,t is the participant's income in that round; BegBali,t is the participant's cumulative earnings by round i; $\mathrm{Hi}$ _Costi,t and Lo_Costi,t are dummy variables indicating the high-cost and low-cost treatments; ui is the subject-specific dummy variable; and ei,t is a standard normal error term. The regression results are presented in Table 2. These results confirm the conclusions drawn from the summary statistics and graphical analysis. Our results support our conjecture, based on the Alchian and Allen argument, that high costs of being audited will lead to lower compliance rates rather than higher.

Table 2. Regression results

\begin{tabular}{lcll} 
Variable & Estimated coefficient & SE & $p$-Value \\
\hline Constant & 0.432 & 0.053 & 0.000 \\
Inc $_{i, t}$ & -0.009 & 0.012 & 0.434 \\
BegBal $_{i, t}$ & -0.004 & 0.0004 & 0.000 \\
Hi_Cost & 0.051 & 0.051 & 0.313 \\
Lo_Cost $_{i, t}$ & -0.156 & 0.049 & 0.002 \\
Wald & 118.47 & & 0.000 \\
$N$ & 950 & &
\end{tabular}

\section{Conclusion}

Our results suggest that the IRS would do well to reduce the fixed costs (absent penalties for evasion) of audits to individual taxpayers. It would appear that the Alchian and Allen argument applies to tax compliance as it does to shipping only high-quality local produce from the region in which it is produced. Our results should be considered as suggestive given the small range of costs investigated. However, a consistent pattern of behaviour does appear and this warrants further investigation since the policy implications appear to be considerable. 
Alchian, A. and W. Allen (1966). Exchange and Production: Theory in Use B2 - Exchange and Production: Theory in Use. Belmont, CA, Wadsworth Publishers.

Allingham, M. G. and A. Sandmo (1972). Income tax evasion: A theoretical analysis. 1.

Alm, J., et al. (1992). Estimating the determinants of taxpayer compliance with experimental data. 45.

Camerer, C. (1995). Individual decision making. Handbook of Experimental Economics B2 - Handbook of Experimental Economics. Princeton, NJ, Princeton University Press.

Machina, M. J. (1987). Choice under uncertainty: Problems solved and unsolved. 1.

Slemrod, J. and J. Bakija (1996). Taxing Ourselves: A Citizen's Guide to the Great Debate over Tax Reform B2 - Taxing Ourselves: A Citizen's Guide to the Great Debate over Tax Reform. Cambridge, MA, MIT Press. 